\title{
Small Aggregates of Tumor Cells Present
}

National Cancer Institute

\section{Source}

National Cancer Institute. Small Aggregates of Tumor Cells Present. NCI Thesaurus. Code C150395.

A morphologic finding indicating the presence of small aggregates of tumor cells in a tissue sample. 